\title{
THE
}

\section{Rapid Eddy-Induced Modification of Subtropical Mode Water During the Kuroshio Extension System Study}

\author{
Stuart P. Bishop \\ D. Randolph Watts \\ University of Rhode Island, randywatts@uri.edu
}

Follow this and additional works at: https://digitalcommons.uri.edu/gsofacpubs

Terms of Use

All rights reserved under copyright.

\section{Citation/Publisher Attribution}

Bishop, Stuart P.; Watts, D. Randolph. (2014). "Rapid Eddy-Induced Modification of Subtropical Mode Water during the Kuroshio Extension System Study." Journal of Physical Oceanography. 44(7): 1941-1953. Available at: http://dx.doi.org/10.1175/JPO-D-13-0191.1

This Article is brought to you for free and open access by the Graduate School of Oceanography at DigitalCommons@URI. It has been accepted for inclusion in Graduate School of Oceanography Faculty Publications by an authorized administrator of DigitalCommons@URI. For more information, please contact digitalcommons-group@uri.edu. 


\title{
Rapid Eddy-Induced Modification of Subtropical Mode Water during the Kuroshio Extension System Study
}

\author{
STUART P. BISHOP \\ National Center for Atmospheric Research, ${ }^{*}$ Boulder, Colorado \\ D. RANDOLPH WATTS \\ Graduate School of Oceanography, University of Rhode Island, Narragansett, Rhode Island
}

(Manuscript received 5 September 2013, in final form 21 April 2014)

\begin{abstract}
From 2004 to 2006 an observational array of current- and pressure-recording inverted echo sounders (CPIES) were deployed as part of the Kuroshio Extension (KEx) System Study (KESS). KESS observed a transition from a weakly meandering ("stable") to strongly meandering ("unstable") state (Qiu and Chen). As the KEx made this transition, potential vorticity (PV) observed within the southern recirculation gyre (SRG) rapidly increased from January to July 2005. In this study, the authors diagnose eddy PV fluxes (EPVFs) in isentropic coordinates within the subtropical mode water (STMW) layer from the CPIES data to determine the role of mesoscale eddies in this rapid increase of PV.

The rapid increase in PV within the SRG coincided with enhanced cross-front EPVFs and eddy PV flux convergence upstream of a mean trough in the KEx path and adjacent to the SRG. The enhanced cross-front EPVFs were the result of the formation of a cold-core ring (CCR) and the interaction of the jet with a preexisting CCR. Eddy diffusivities are diagnosed for the unstable regime with values that range from 100 to $2000 \mathrm{~m}^{2} \mathrm{~s}^{-1}$. The high eddy diffusivities during the unstable regime reflect the nature of mesoscale CCR formation and CCR-jet interaction as efficient mechanisms for stirring and mixing high PV waters from the north side of the KEx into the low PV waters of the SRG where STMW resides. This mechanism for crossfrontal exchange can explain observed increases in the STMW PV in the SRG over the 16 months of KESS observations.
\end{abstract}

\section{Introduction}

The Kuroshio is the western boundary current (WBC) of the northwest Pacific. It flows north from the tropics carrying heat and momentum along the western boundary and breaks from the coast of Japan at $\sim 35^{\circ} \mathrm{N}$ where it flows east as a free jet, renamed the Kuroshio Extension (KEx). The KEx is a vigorously meandering frontal boundary, characterized as one of the regions of highest eddy kinetic energy (EKE) in the ocean, separating warm salty subtropical

\footnotetext{
* The National Center for Atmospheric Research is sponsored by the National Science Foundation.

Corresponding author address: Stuart P. Bishop, National Center for Atmospheric Research, P.O. Box 3000, Boulder, CO 80307. E-mail: sbishop@ucar.edu
}

waters to the south from cold fresh subpolar waters to the north.

The KEx is also a potential vorticity (PV) front with high PV to the north and low to the south in the upper ocean. From hydrographic feature surveys, the KEx front naturally separates into four vertical PV layers associated with key characteristics: an upper layer located between the seasonal and main thermocline containing subtropical mode water (STMW), the main thermocline layer, the lower thermocline layer containing North Pacific Intermediate Water (NPIW), and a deep weakly stratified and laterally well mixed layer (Howe et al. 2009).

The focus of this paper will be on the STMW layer. STMW is a low PV water mass of nearly constant temperature $\left(17^{\circ} \mathrm{C}\right)$ that forms during late winter from convective cooling and mixing at the surface, which deepens the mixed layer, increasing its thickness and decreasing its PV [see Oka and Qiu (2012) for 
a review]. Summertime surface heating caps the top of the STMW layer, separating it from surface forcing and allowing the water mass to freely evolve and subduct into the southern recirculation gyre (SRG). There are still many open questions about what processes drive the formation and evolution of STMW. This question motivated recent observational field campaigns in the KEx, the KEx System Study (KESS) (Donohue et al. 2008), and Gulf Stream, Climate Variability and Predictability (CLIVAR) Mode Water Dynamic Experiment (CLIMODE) (Marshall et al. 2009).

One mechanism suggested by Cronin et al. (2013) to modify STMW after summertime surface heating caps the STMW layer would be large diapycnal diffusion of heat downward at the base of the mixed layer by inertial shear when tropical cyclones and winter storms pass. A new theory on mode water maintenance (Deremble and Dewar 2013) emphasizes that eddy mechanics are central to mode water maintenance, which contrasts sharply with other theories that do not include eddies (Dewar et al. 2005). Eddy-resolving simulations from the Parallel Ocean Program have also shown that the distribution of STMW is highly dependent upon eddies (Rainville et al. 2007).

An important aspect of the KEx system is that the mesoscale variability in the first $1000 \mathrm{~km}$ east of Japan modulates on decadal time scales between stable and unstable regimes characterized by minimal meandering and vigorous meandering, respectively (Qiu and Chen 2005). During the unstable regime there is enhanced eddy variability including cold-core rings (CCRs) and heightened cross-frontal eddy heat fluxes between $144^{\circ}$ and $148^{\circ} \mathrm{E}$ (Bishop 2013). The mean jet has a weaker transport and weaker circulation in the SRG during the unstable regime (Qiu and Chen 2005). PV within the STMW layer was also observed to increase during unstable regimes (Qiu et al. 2006, 2007).

Recent studies have shown that STMW interannual variability is linked to the dynamic state of the KEx rather than through variations in atmospheric forcing (Qiu and Chen 2006). During KESS from 2004 to 2006 Qiu et al. (2007), using satellite altimetry and Argo float observations, found that modification of STMW in the SRG could possibly be explained by diffusion of high PV waters from the core of an already detached CCR residing within the SRG, which carried high PV waters from the north side of the KEx. Through a diffusive model, the authors hypothesized that a modest eddy diffusivity of $300 \mathrm{~m}^{2} \mathrm{~s}^{-1}$ could explain increased values of PV in the STMW region of the SRG outside of the CCR. This process was relatively quick, acting over a few months from January to June 2005. The authors argued that PV fluxes from the CCR to the adjacent, low PV waters would be through an instability process of the ring since it would meet the necessary conditions for baroclinic instability.

In this paper we present an alternative or additional mechanism for modifying STMW within the SRG. We show that cross-frontal advection of high PV waters from the north side of the KEx to the SRG by mesoscale eddies during the formation and detachment process of CCRs are responsible for the increase in SRG PV during KESS. A key distinction from Qiu et al. (2007)'s study is that the cross-frontal exchange of PV occurred upstream of the CCR formation and detachment region, not related to the CCR carrying a high PV core into the SRG. The 16 months of directly observed large cross-front eddy PV fluxes (EPVFs) diagnosed from current- and pressure-recording inverted echo sounders (CPIES) show that divergent eddy thickness fluxes by mesoscale eddies bring high PV waters from the northern side of the KEx to the low PV southern side. These 16 months are certainly not long enough to obtain stable eddy statistics (Flierl and McWilliams 1977). It would take many years of observations, in light of observed decadal variability, to obtain stable statistics. To our knowledge these are the first estimates of EPVFs from observations in the KEx. We treat this study as a process-based study to understand the role of cross-front EPVFs in the rapid increase of STMW in the SRG during KESS.

The goals of this paper are to present the eddy PV balance within the STMW layer in the KEx region from observations, diagnose eddy diffusivities within this layer, and use the estimates of eddy diffusivity to determine the role of mesoscale eddies in modification of STMW during KESS. The outline of the paper is now set forth. Section 2 describes the KESS CPIES dataset. Section 3 introduces PV dynamics in isentropic coordinates, in which we show that the CPIES data give a robust estimate of the eddy PV balance in the KEx. Section 4 describes the methods for decomposing the EPVFs into divergent and rotational components and the diagnosis of eddy diffusivity. Here we present the rational for decomposing EPVFs and why the divergent component is needed for diagnosing eddy diffusivity. It is further shown that eddy diffusivities from the crossfront component of EPVF represent irreversible mixing and stirring of water parcels (Abernathey and Marshall 2013), which is the component we are interested in diagnosing to determine the modification of STMW. Section 5 then uses the results of eddy diffusivity in section 4 to determine the role of eddies in the modification of STMW. The conclusions are in the final section. 


\section{KESS}

\section{a. Data}

There were 46 CPIES deployed in a $\sim 600 \mathrm{~km} \times$ $600 \mathrm{~km}$ array spanning the KEx jet for $2 \mathrm{yr}$ from 2004 to 2006 during KESS (Fig. 1). The CPIES array was centered in the region of highest surface EKE from satellite altimetry $\left(143^{\circ}-149^{\circ} \mathrm{E}\right)$ and spanned the meander envelope from north to south, capturing almost one full wavelength of the quasi-stationary meander cresttrough-crest east of Japan (Mizuno and White 1983).

The KESS array provided full maps of geostrophic current, salinity, temperature, and density for 16 months from June 2004 to September 2005, after which some CPIES stopped working early. The CPIES data were twice-daily averaged and 3-day low-pass filtered using a fourth-order Butterworth filter to remove tidal influences. For additional details on the CPIES processing and instrumentation see Donohue et al. (2010).

\section{b. Subtropical mode water layer}

The STMW isentropic layer is modeled after Howe et al. (2009)'s work and defined as the layer between 25.1 and $25.5 \sigma_{\theta}$. The quantities $\mathbf{u}$ and $\sigma_{\theta}$ were mapped on a $1 / 8^{\circ}$ latitudinal and longitudinal grid at level surfaces every $20 \mathrm{~m}$ in the vertical for the upper ocean (surface to $1000 \mathrm{~m}$ ) for 16 months. The layer thickness $h$ at each grid point was estimated daily for 16 months by finding the depth of the two isentropic surfaces using linear interpolation of density profiles that were gridded at 10-m intervals and taking the difference between the deeper $\sigma_{\theta_{2}}$ and shallower-layer $\sigma_{\theta_{1}}$ :

$$
h=Z_{z=\sigma_{\theta_{2}}}-Z_{z=\sigma_{\theta_{1}}},
$$

where $Z$ is the depth of the isentropic surface. The geostrophic velocity $\mathbf{u}$ for each layer was estimated daily at each grid point as a depth average between isentropic surfaces. The daily layer thickness uncertainty $\delta h$ is $O(25) \mathrm{m}$ and for the mean $O(5) \mathrm{m}$. This study only focuses on regions where $\delta h / \bar{h}$ is less than $15 \%$.

\section{c. Timeline of events during KESS}

The sequence of events during KESS is described in Bishop (2013) and is again summarized here. The KESS experiment exhibited a range of mesoscale processes. The first 6 months from June to November 2004 were characterized by the stable meandering regime. Tracey et al. (2012) showed that this regime was dominated by small-amplitude, $\sim 50 \mathrm{~km}$, peak-to-peak, lateral displacement, upper-baroclinic frontal waves with periods of $10-15$ days. These waves traversed the KESS array from the west to east with phase speeds of
$20-25 \mathrm{~km} \mathrm{day}^{-1}$ and wavelengths of $200-300 \mathrm{~km}$ that exhibited meander growth at times when coupling to deep eddies.

After November, the KEx transitioned from a stable to unstable meandering regime with the formation of a CCR and remained in this state for the subsequent 10 months of observations. During the unstable regime, longer period meanders in the 30-60-day band began to propagate into the KESS array traveling west to east with average periods of $43.5 \pm 3.7$ days, propagation speeds of $9.6 \mathrm{~km} \mathrm{day}^{-1}\left(7.8-12.1 \mathrm{~km} \mathrm{day}^{-1}\right)$, and wavelengths of $418 \pm 60 \mathrm{~km}$ (Tracey et al. 2012). When the longer period upper meanders appeared, simultaneously trains of deep, externally generated eddies in the 30-60-day band, with a nominal period of $\sim 40$ days, began propagating into the KESS array from the eastnortheast and turned approximately following bathymetry contours to travel down the central line from the northeast to the southwest. These eddies interacted with the jet, and a detailed study of this process is given in Greene et al. (2012). Following the formation of the CCR that marked the meandering regime transition, another CCR that had formed downstream interacted with the KEx jet within the KESS observational array. The CCRs are further discussed in a later section on the modification of STMW.

\section{Potential vorticity}

\section{a. Eddy potential vorticity balance}

In this section, we derive the eddy PV balance in isentropic coordinates. It has been suggested that stirring and mixing by eddies in a rotating and stably stratified fluid away from boundaries occurs primarily along isopycnal surfaces rather than level or pressure surfaces (Iselin 1939; Montgomery 1940), and parameterizations of mesoscale eddy fluxes have taken this approach (Gent and McWilliams 1990).

To study the effects of EPVFs on the modification of water masses, it is ideal to work in isentropic coordinates. Within layers determined by two potential density surfaces, that is, an isentropic layer, the PV equation in the absence of external torques (i.e., wind stress curl at the surface from isopycnal surfaces outcropping, diabatic processes, and negligible diapycnal mixing) is

$$
\frac{\partial q}{\partial t}+\mathbf{u} \cdot \nabla_{b} q=0
$$

where $q$ is the PV for the layer,

$$
q=\frac{f+\zeta}{h}
$$




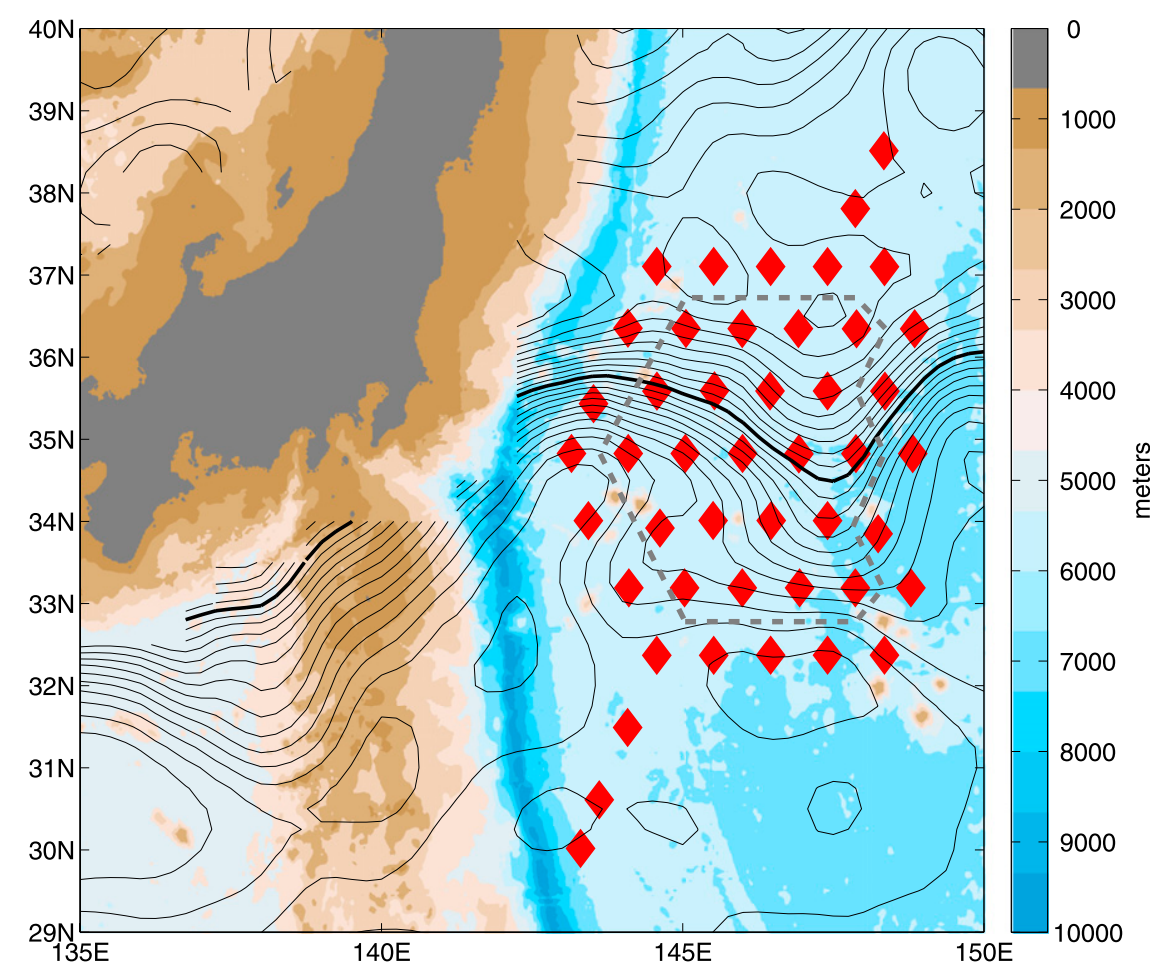

FIG. 1. KESS observing array. Red diamonds are the locations of CPIES. Color shades indicate ocean bathymetry from Smith and Sandwell (1997). Black contours are the mean SSH contours $[0.05 \mathrm{~m}$ contour interval (ci)] from the satellite altimetry Archiving, Validation, and Interpretation of Satellite Oceanographic data (AVISO) product with RIO05 mean dynamic topography over the duration of the KESS experiment (June 2004-July 2006). The thick black contour is representative of the jet axis (2.1-m SSH contour). Only the CPIES sites within the gray dashed contour are used in this study.

$\nabla_{b}$ is the horizontal gradient operator acting along isopycnal surfaces, $\zeta=\mathbf{k} \cdot \nabla_{b} \times \mathbf{u}$ is the local vertical layer relative vorticity, and $h$ is the layer thickness. The layer thickness satisfies continuity:

$$
\frac{\partial h}{\partial t}+\nabla_{b} \cdot(\mathbf{u} h)=0
$$

which is analogous to continuity for the shallow-water equations [see Cushman-Roisin and Beckers (2011) for details on the derivation of this version of continuity]. Following Ringler and Gent (2011), the conservative form of the PV equation that satisfies theorems found in Haynes and McIntyre (1987, 1990) is the thicknessweighted PV equation:

$$
\frac{\partial h q}{\partial t}+\nabla_{b} \cdot(\mathbf{u} h q)=0 .
$$

The steady-state PV equation for conservative flow is achieved by decomposing the fields into time mean and eddy terms, which are perturbations from the time mean, in Eq. (5) and taking a time mean:

$$
\mathbf{U} \bar{h} \cdot \nabla_{b} \bar{q}=-\nabla_{b} \cdot\left(\overline{\mathbf{u}^{\prime} q^{\prime}} \bar{h}\right),
$$

where bars indicate a time mean and primes indicate eddy terms. To arrive at Eq. (6), steady-state continuity,

$$
\nabla_{b} \cdot \mathbf{U} \bar{h}=0,
$$

was used, where $\mathbf{U}=\overline{\mathbf{u}}+\mathbf{u}^{*}$ is the sum of the mean and bolus velocity,

$$
\mathbf{u}^{*}=\frac{\overline{\mathbf{u}^{\prime} h^{\prime}}}{\bar{h}},
$$

and terms of $O\left(\mathrm{Ro}^{2}\right)$ were neglected. This equation relates the mean flow to EPVFs and is sometimes referred to as the "eddy Sverdrup" equation (Jayne et al. 1996) because of its close correspondence with the Sverdrup equation.

An approximation to the mean and eddy PV terms for small variations in layer thickness, $h^{\prime} / \bar{h} \ll 1$, and quasigeostrophic (QG) scaling is

$$
q=\bar{q}+q^{\prime}=\frac{f}{\bar{h}}+\frac{\bar{\zeta}}{\bar{h}}+\frac{\zeta^{\prime}}{\bar{h}}-f_{0} \frac{h^{\prime}}{\bar{h}^{2}}+O\left(\mathrm{Ro}^{2}\right)
$$


where $f=f_{0}+\beta y$ on a beta plane, $f_{0}=8.36 \times 10^{-5} \mathrm{~s}^{-1}$ is evaluated at $35^{\circ} \mathrm{N}$, and $\beta=d f / d y=2 \times 10^{-11} \mathrm{~m}^{-1} \mathrm{~s}^{-1}$. The time-mean PV is

$$
\bar{q}=\frac{f+\bar{\zeta}}{\bar{h}}
$$

and the eddy PV is

$$
q^{\prime}=\frac{\zeta^{\prime}-f_{0} h^{\prime} / \bar{h}}{\bar{h}} .
$$

From these approximations, the EPVFs are

$$
\overline{\mathbf{u}^{\prime} q^{\prime}}=\frac{\overline{\mathbf{u}^{\prime} \zeta^{\prime}}}{\bar{h}}-f_{0} \overline{\overline{\mathbf{u}^{\prime} h^{\prime}}} \overline{\bar{h}^{2}}
$$

where the velocity field $\mathbf{u}$ is geostrophic under QG considerations. The first term on the RHS is the eddy PV relative vorticity flux, and the second term is the eddy PV thickness flux.

\section{b. Mean eddy potential vorticity balance from CPIES data}

The 16-month mean eddy PV balance is diagnosed from the CPIES data within the STMW layer. Mean PV [Eq. (10)] is decomposed into thickness and relative vorticity in Fig. 2. To the first-order, mean thickness PV $\bar{q} \approx f / \bar{h}$ dominates the mean PV balance with mean relative vorticity $\bar{\zeta} / \bar{h}$ ranging from $\pm 1 \times 10^{-7} \mathrm{~m}^{-1} \mathrm{~s}^{-1}$ (Fig. 2c), while mean thickness $f / \bar{h}$ ranges from 2 to $10 \times$ $10^{-7} \mathrm{~m}^{-1} \mathrm{~s}^{-1}$ (Fig. 2b).

The eddy PV balance [Eq. (6)] within the STMW layer is verified in Fig. 3 showing that the CPIES data give a robust estimate of this balance. There is strong convergence of eddy PV flux upstream of the mean trough $\sim 147^{\circ} \mathrm{E}$ (Fig. 3b) that corresponds with positive mean advection of PV (Fig. 3a) in a region of the jet adjacent to the SRG. There is also strong divergence of eddy PV flux downstream of the mean trough $\sim 147^{\circ} \mathrm{E}$ (Fig. 3b), which too corresponds with negative mean advection of $\mathrm{PV}$ (Fig. 3a). The zonal average of Figs. 3a and 3b nearly balances with some small residual (Fig. 3c).

\section{Eddy potential vorticity fluxes}

\section{a. Divergent fluxes}

It is important to decompose EPVFs into divergent and rotational (nondivergent) components when looking at their contributions to eddy-mean flow interactions (Marshall and Shutts 1981). We first present our method for decomposing eddy fluxes and then in the next section demonstrate the importance for this decomposition in determining eddy diffusivities. A method that can be used to decompose EPVFs into "purely" rotational and divergent components,

$$
\overline{\mathbf{u}^{\prime} q^{\prime}}={\overline{\mathbf{u}^{\prime} q^{\prime}}}^{\text {div }}+{\overline{\mathbf{u}^{\prime} q^{\prime}}}^{\text {rot }},
$$

is through objective analysis (OA), using nondivergent correlation functions (Bishop and Watts 2013; D. R. Watts and K. L. Tracey 2013, unpublished manuscript). The OA method maps the best-fit nondivergent vector field to the total EPVF field. A correlation length scale of $75 \mathrm{~km}$ was used, which is consistent with the correlation length scale used in mapping the current and temperature field (Donohue et al. 2010). The divergent component of the EPVF is determined by taking the difference between the full vector field and the best-fit nondivergent field from the OA:

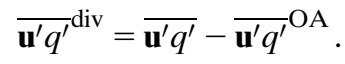

Using the OA method, Fig. 4 shows the decomposition of the EPVFs into rotational and divergent components. The full eddy PV thickness flux $-f_{0} \overline{\mathbf{u}^{\prime} h^{\prime}} / \bar{h}^{2}$ has comparable rotational and divergent components (Figs. 4b,c), while the total eddy PV relative vorticity flux $\overline{\mathbf{u}^{\prime} \zeta^{\prime}} / \bar{h}$ is clearly dominated by the rotational component(Figs. $4 \mathrm{~d}-\mathrm{f})$. The result suggests

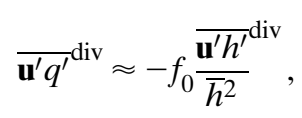

since the divergent component of the eddy PV relative vorticity flux is much smaller than the divergent eddy PV thickness flux in the STMW layer.

\section{b. Eddy enstrophy dissipation and eddy diffusivity}

The goal of this section is to estimate eddy diffusivity $\kappa$ for PV within the STMW layer and show that the crossfront divergent EPVFs are associated with irreversible mixing. Our estimate of $\kappa$ will be used in the next section to diagnose eddy-induced modification to STMW water in the SRG during the unstable regime. Eddy fluxes in oceanic models that cannot resolve mesoscale eddies are parameterized as downgradient fluxes proportional to an eddy diffusivity (Gent and McWilliams 1990). Here we adopt this approach for EPVFs and parameterize them as

$$
{\overline{\mathbf{u}^{\prime} q^{\prime}}}^{\mathrm{div}}=-\mathbf{K} \nabla \bar{q},
$$

where

$$
\mathbf{K}=\underbrace{\left(\begin{array}{cc}
\kappa & 0 \\
0 & \kappa
\end{array}\right)}_{\text {symmetric }}+\underbrace{\left(\begin{array}{cc}
0 & -\nu \\
\nu & 0
\end{array}\right)}_{\text {antisymmetric }}
$$



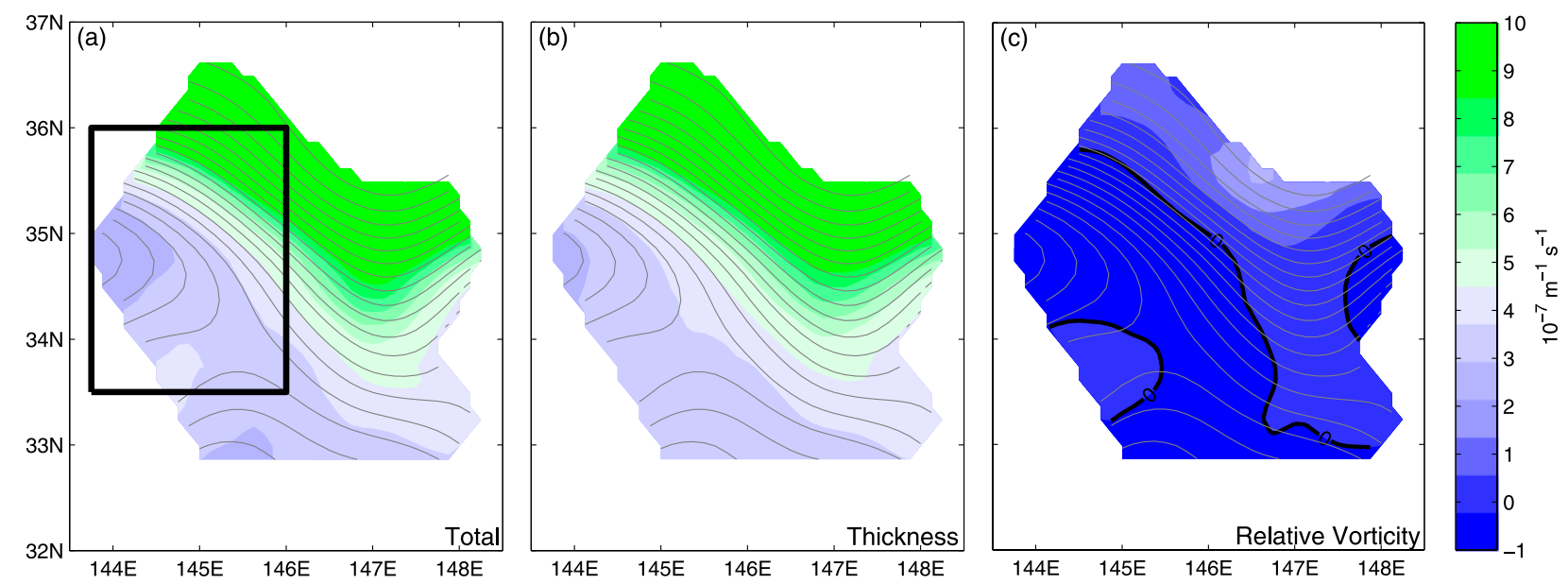

FIG. 2. The 16-month time-mean PV between isentropic surfaces 25.1 and $25.5 \sigma_{\theta}$ for (a) total, (b) thickness, and (c) relative vorticity. Gray contours are Montgomery potential $\left(\mathrm{ci}=0.5 \mathrm{~m}^{2} \mathrm{~s}^{-2}\right)$. The thick black box in (a) is the region of averaging for the SRG later in the paper.

is the two-dimensional eddy diffusivity tensor made up of symmetric and antisymmetric components [see FoxKemper et al. (2013) for a review of lateral transport by eddies in the ocean interior]. Note that the parameterization is for the divergent component of EPVF, since the rotational component plays no role in eddy-mean flow interactions, and it is the divergence of EPVF that affects the mean flow [Eq. (6)]:

$$
-\nabla \cdot \overline{\mathbf{u}^{\prime} q^{\prime}}=\nabla \cdot \mathbf{K} \nabla \bar{q}
$$

Studies have shown that eddy diffusivities estimated from the "raw" fluxes versus divergent fluxes grossly overestimate eddy diffusivities and may give results with opposite sign (Eden et al. 2007). It will be shown below that the eddy diffusivity estimated from the cross-front divergent fluxes is the eddy diffusivity that represents mixing and diabatic effects associated with mesoscale eddies. To demonstrate this we start with the steadystate eddy enstrophy $\overline{q^{\prime 2}} / 2$ equation:

$$
\overline{\mathbf{u}} \cdot \nabla \frac{1}{2} \overline{q^{\prime 2}}=-\overline{\mathbf{u}^{\prime} q^{\prime}} \cdot \nabla \bar{q}-\nabla \cdot \frac{1}{2} \overline{\mathbf{u}^{\prime} q^{\prime 2}}+\overline{D^{\prime} q^{\prime}}
$$

where the term $\overline{D^{\prime} q^{\prime}}$ represents sources or sinks of PV due to dissipation or forcing in the system by mixing and diabatic effects. For completeness, the triple correlation term has been included, but is often neglected in most studies. Both Waterman and Jayne (2011) and Cronin and Watts (1996) find that the triple correlation term, in terms of eddy enstrophy and eddy potential energy, respectively, is likely not negligible in the WBC extensions. Wilson and Williams (2004) also show that the
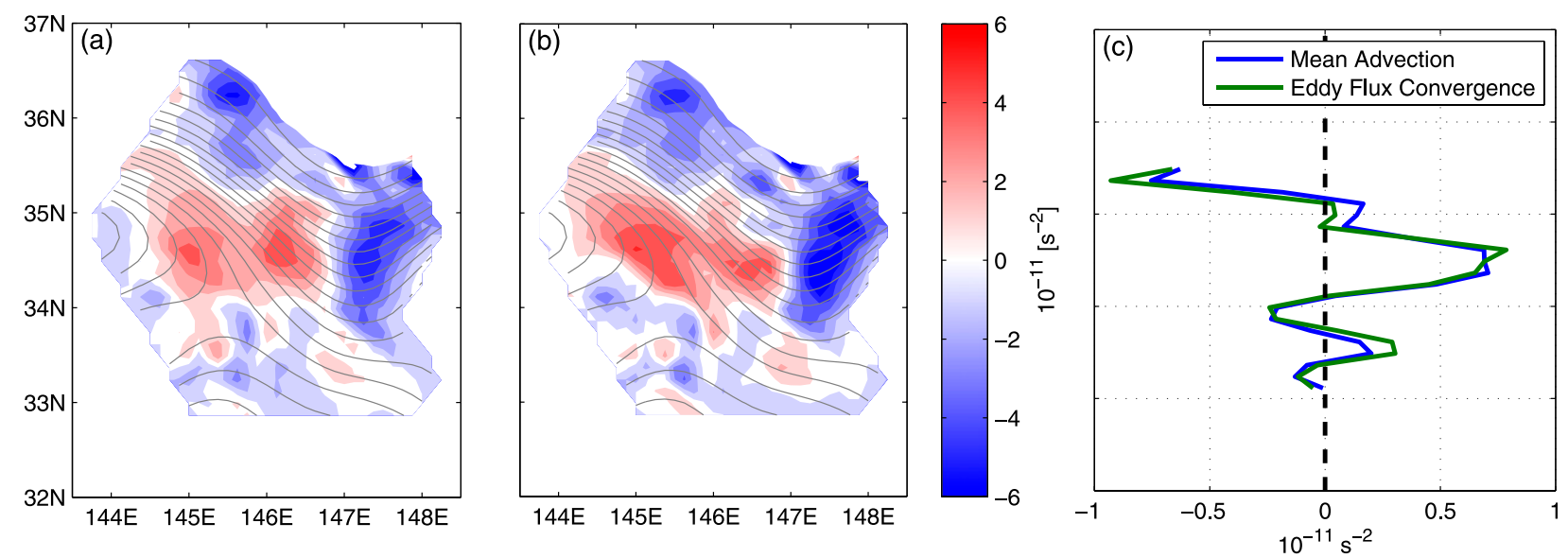

FIG. 3. The 16-month time-mean PV balance [Eq. (6)]. (a) Mean advection of PV, $\mathbf{U} \bar{h} \cdot \nabla_{b} \bar{q}$. (b) Convergence of thickness-weighted eddy $\mathrm{PV},-\nabla_{b} \cdot\left(\overline{\mathbf{u}^{\prime} q^{\prime}} \bar{h}\right)$. Gray contours in (a) and (b) are Montgomery potential (ci $\left.=0.5 \mathrm{~m}^{2} \mathrm{~s}^{-2}\right)$. (c) Zonal average of terms in (a) and (b). 

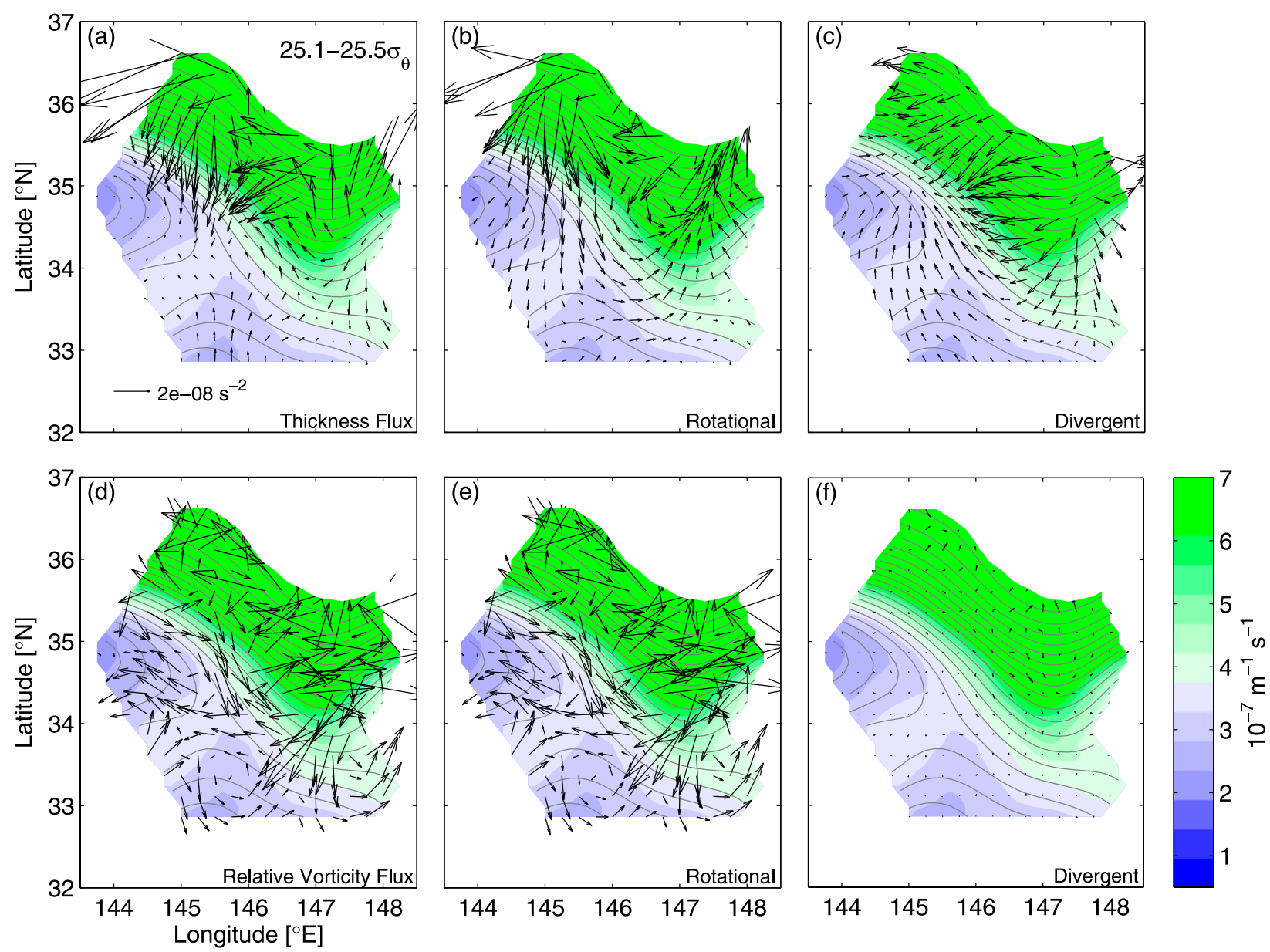

FIG. 4. Divergent vs rotational EPVFs. The 16-month mean eddy thickness flux, $-f_{0} \overline{\mathbf{u}^{\prime} h^{\prime}} / \bar{h}^{2}$, vectors for the (a) total flux, (b) rotational flux, and (c) divergent flux between isentropic surfaces 25.1-25.5 $\sigma_{\theta}$. Gray contours are Montgomery potential $\left(\mathrm{ci}=0.5 \mathrm{~m}^{2} \mathrm{~s}^{-2}\right)$. Superimposed in color is the 16-month mean PV, f/ $\bar{h}$, with ci $=0.5 \times 10^{-7} \mathrm{~m}^{-1} \mathrm{~s}^{-1}$. (d)-(f) As in (a)-(c), but for eddy relative vorticity flux $\overline{\mathbf{u}^{\prime} \zeta^{\prime}} / \bar{h}$.

triple correlation term becomes significant in regions of high eddy enstrophy, for example, WBC regions. Next, we can neglect mean advection of enstrophy [LHS term in Eq. (19)] based on the arguments in Marshall and Shutts (1981) that the large rotational component of EPVF balances the mean advection of eddy enstrophy and does not contribute to eddy-mean flow interactions:

$$
\overline{\mathbf{u}} \cdot \nabla \frac{1}{2}{\overline{q^{\prime 2}}}+{\overline{\mathbf{u}^{\prime} q^{\prime}}}^{\mathrm{rot}} \cdot \nabla \bar{q}=0,
$$

where the rotational fluxes are proportional to eddy enstrophy,

$$
{\overline{\mathbf{u}^{\prime} q^{\prime}}}^{\mathrm{rot}}=\gamma_{q} \mathbf{k} \times \nabla \overline{q^{\prime 2}}
$$

Equation (21) requires $\gamma_{q} \equiv d \bar{\psi} / d \bar{q}$ is constant (there is a negative linear relationship between the mean streamfunction $\bar{\psi}$ and mean PV $\bar{q}$ ), and Eq. (20) was confirmed (not shown). The remaining balance in Eq. (19) is now between cross-front divergent EPVFs, the triple correlation term, and mixing through diabatic processes:

$$
-\overline{\mathbf{u}^{\prime} q^{\prime}} \operatorname{div} \cdot \nabla \bar{q}=\nabla \cdot \frac{1}{2} \overline{\mathbf{u}^{\prime} q^{\prime 2}}-\overline{D^{\prime} q^{\prime}} .
$$

By decomposing the divergent EPVFs [Eq. (16)] into cross- and alongfront components with respective unit vectors $\mathbf{n}$ and $\mathbf{s}$, where $\mathbf{n}=\nabla \bar{q}|\nabla \bar{q}|^{-1}$ and $\mathbf{s}=\mathbf{n} \times \mathbf{k}$ and $\mathbf{k}$ is the vertical unit vector, it can be shown that the cross-front component is associated with the symmetric eddy diffusivity tensor. The LHS of Eq. (22) can then be written as

$$
-{\overline{\mathbf{u}^{\prime} q^{\prime}}}^{\operatorname{div}} \cdot \nabla \bar{q}=\kappa|\nabla \bar{q}|^{2} .
$$

Rearranging using Eqs. (22) and (23), an equation for eddy diffusivity can written as 


$$
\kappa=\left(\nabla \cdot \frac{1}{2} \overline{\mathbf{u}^{\prime} q^{\prime 2}}-\overline{D^{\prime} q^{\prime}}\right)|\nabla \bar{q}|^{-2} .
$$

Assuming diabatic processes and external forcing are always dissipative, $\overline{D^{\prime} q^{\prime}}<0$, eddy diffusivity is negative (upgradient) only when there is a convergence of eddy enstrophy flux, $\boldsymbol{\nabla} \cdot(1 / 2) \overline{\mathbf{u}^{\prime} q^{\prime 2}}<0$ and $\left|\boldsymbol{\nabla} \cdot(1 / 2) \overline{\mathbf{u}^{\prime} q^{\prime 2}}\right|>$ $\left|\overline{D^{\prime} q^{\prime}}\right|$. For linear dynamics the triple correlation term is negligible and eddy diffusivity is always positive:

$$
\kappa \approx\left|\overline{D^{\prime} q^{\prime}}\right||\nabla \bar{q}|^{-2} .
$$

The end result is that cross-front divergent EPVFs lead to dissipation through irreversible eddy mixing and diabatic processes. Entropy dissipation $-\overline{\mathbf{u}^{\prime} q^{\prime}}{ }^{\text {div }}$. $\nabla \bar{q}$ and eddy diffusivity $\kappa$ that was calculated from Eq. (23) are shown in Fig. 5 for the unstable period between November 2004 and September 2005. Figure 5a shows that divergent PV fluxes are mostly downgradient and that enstrophy dissipation occurs largely along the mean path of the KEx jet upstream of a mean trough and adjacent to the SRG. Here mostly downgradient means that the contribution of EPVFs to eddy-mean flow interaction is mainly due to the downgradient component. The cross-frontal divergent EPVFs lead to large eddy diffusivities in excess of $1000 \mathrm{~m}^{2} \mathrm{~s}^{-1}$ in the same region where enstrophy dissipation is large (Fig. 5b).

\section{Modification of subtropical mode water}

Based on the strong downgradient divergent EPVFs observed in the STMW layer (Fig. 5a), the rate of PV influx to the SRG due to eddies and their role in STMW modification will be determined in this section using the estimate of eddy diffusivity from the previous section. An alternative or additional mechanism to Qiu et al. (2007) for modifying STMW within the SRG is suggested here due to the influx of PV by eddies that bring high PV waters from the northern side of the KEx to the southern side. This cross-frontal exchange of high PV waters is mainly in the region upstream of the mean trough of the current path, $\sim 147^{\circ} \mathrm{E}$, and adjacent to the SRG. Interestingly, maps of EPVF convergence (Fig. 6) show no significant convergence associated with the CCR south of the jet near the SRG that had been hypothesized in Qiu et al. (2007), which if present would have indicated instability processes associated with the CCR.

To see what role the cross-frontal EPVFs play in driving changes in STMW, we follow the work by Qiu et al. (2007) and show that PV within the SRG is modified by eddy diffusion. The equation is derived by taking the area integral of the PV equation $\left\{\int_{A}[(\partial Q / \partial t)+J(\psi, Q)=\right.$ $\nabla \cdot \kappa \nabla Q] d A\}:$

$$
\frac{\partial Q_{\mathrm{RG}}}{\partial t}=A^{-1} \int_{\psi_{\mathrm{RG}}} \kappa \nabla Q \cdot \mathbf{n} d l .
$$

The term $Q_{\mathrm{RG}}$ is the area-averaged PV within the SRG:

$$
Q_{\mathrm{RG}}=A^{-1} \int_{A} Q d A,
$$

where $A$ is the surface area of the SRG, defined as the area enclosed by geopotential height referenced to 5300 dbar greater than $4.4 \mathrm{~m}, \psi_{\mathrm{RG}}$, within the box in Fig. 2 to exclude high PV contributions from CCRs. The integral can be pulled inside the time derivative, since the time rate of change of the SRG area $\partial A / \partial t$ is very small compared to the other terms in the budget. We experimented with the choice of box size and the results did not change [cf. Fig. 7 with Fig. 12 in Qiu et al. (2007) that calculated PV from Argo floats]. The term $Q$ is the $\mathrm{PV}$ along the 25.375- $\sigma_{\theta}$ isopycnal surface as defined by Talley (1988):

$$
Q=\frac{f N^{2}}{g}=\alpha f \frac{\partial T}{\partial z}
$$

where $N$ is the buoyancy frequency, $g$ is the acceleration due to gravity, $\alpha$ is the expansion coefficient, and $T$ is the potential temperature. Here we adopt a different form of PV than in previous sections to be consistent with other work involving STMW, but the two forms of PV are approximately equivalent in the QG limit (Treguier et al. 1997), which is confirmed in Fig. 6. In Fig. 6, the convergence of EPVF for both forms of PV is plotted, and the spatial patterns are consistent with the only difference being the order of magnitude for each form of PV. In the derivation of Eq. (26), the divergence theorem was used, which eliminates the advection of PV $\int_{A} J(\psi, Q) d A=0$, where $J$ is the two-dimensional Jacobian and transforms the eddy diffusion of the PV term to its current form on the RHS:

$$
\int_{A} \nabla \cdot \kappa \nabla Q d A=\int_{\psi_{\mathrm{RG}}} \kappa \nabla Q \cdot \mathbf{n} d l
$$

where $\mathbf{n}$ is the lateral unit vector normal to the surface area of the SRG, and $l$ is the circumference of the SRG.

We next determine the balance of Eq. (26). The time series of $Q_{\mathrm{RG}}$ is shown in Fig. 7. PV is relatively constant between June 2004 and February 2005. Between February and July 2005, there is a large upward trend in PV from $1.25 \times 10^{-10}$ to $1.75 \times 10^{-10} \mathrm{~m}^{-1} \mathrm{~s}^{-1}$ over a 

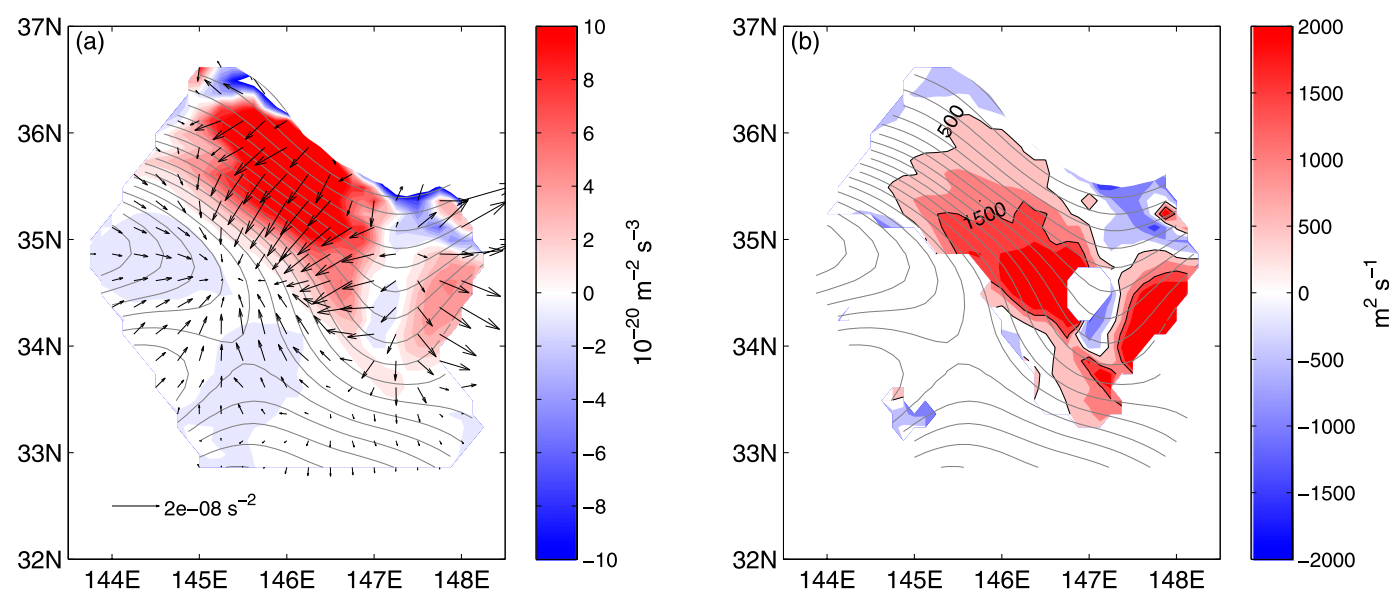

FIG. 5. Eddy enstrophy dissipation and eddy diffusivity in the STMW layer between 25.1- and 25.5- $\sigma_{\theta}$ isentropes. (a) Eddy enstrophy dissipation $-\overline{\mathbf{u}^{\prime} q^{\prime}}$ div $\cdot \nabla \bar{q}$, with divergent EPVF vectors superimposed at every other grid point, and (b) eddy diffusivity $\kappa$ estimated for the unstable period (November 2004-September 2005) with ci $=500 \mathrm{~m}^{2} \mathrm{~s}^{-1}$. Only regions where $|\nabla \bar{q}|>0.2 \times 10^{-11} \mathrm{~m}^{-2} \mathrm{~s}^{-1}$ were considered in the estimate of $\kappa$ to avoid artificially high eddy diffusivities where $\nabla \bar{q} \rightarrow 0$. Gray contours in (a) and (b) are Montgomery potential (ci $=0.5 \mathrm{~m}^{2} \mathrm{~s}^{-2}$ ).

6-month period. After July 2005, PV fluctuates about $\sim 1.6 \times 10^{-10} \mathrm{~m}^{-1} \mathrm{~s}^{-1}$ for the remaining record. The increase in PV after February 2005 corresponds with the transition from a weakly meandering to a strongly meandering state. The slope of $Q_{\mathrm{RG}}$, used as an approximation for $\partial Q_{\mathrm{RG}} / \partial t$, following February 2005 is $0.0037 \times$ $10^{-10} \mathrm{~m}^{-1} \mathrm{~s}^{-1}$ day $^{-1}$ or $4.3 \times 10^{-18} \mathrm{~m}^{-1} \mathrm{~s}^{-2}$ (Fig. 7). The slope is statistically significant with $95 \%$ confidence intervals of $0.0036-0.0039 \times 10^{-10} \mathrm{~m}^{-1} \mathrm{~s}^{-1}$ day $^{-1}$.

The transition from a weakly meandering to strongly meandering state is also reflected in the divergent EPVFs (Fig. 8):

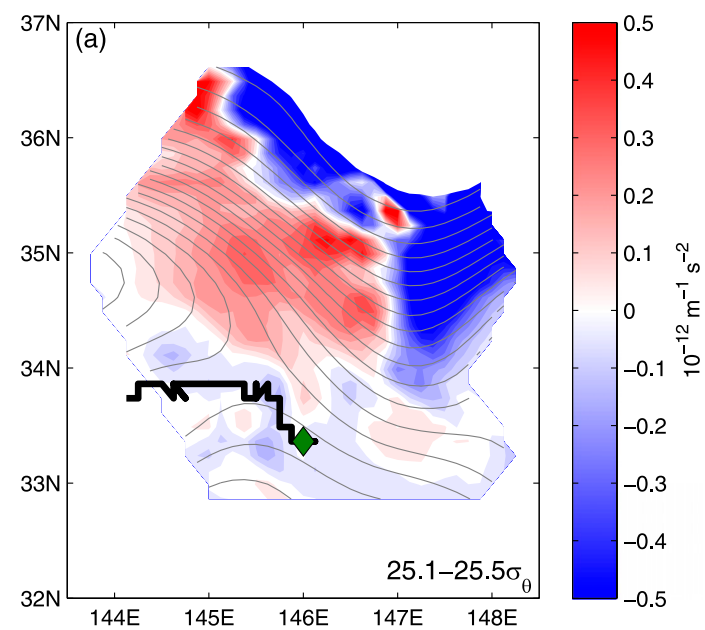

$$
\overline{\mathbf{u}^{\prime} \bar{Q}^{\prime}} \text { div }=\alpha f \frac{\partial{\overline{\mathbf{u}^{\prime} T^{\prime}}}^{\mathrm{div}}}{\partial z}
$$

Figure 8a shows the 16-month time average of EPVFs, which are strongly downgradient. The EPVFs are weak during the first 5 months (Fig. 5b), which corresponded with the weakly meandering state of the KEx. During the remaining record there are large downgradient fluxes of PV upstream of the mean trough and adjacent to the SRG (Fig. 8c). The strong downgradient EPVFs are also associated with the convergence of PV adjacent to the SRG (Fig. 6). The transition to strong cross-front

FIG. 6. Convergence of eddy PV for both forms of PV. (a) $-\nabla \cdot \overline{\mathbf{u}^{\prime} q^{\prime}}$ with $q^{\prime}$ as in Eq. (11). The green diamond and thick black line is the formation and trajectory of the core of the CCR in Qiu et al. (2007). (b) $-\nabla \cdot \overline{\mathbf{u}^{\prime} Q^{\prime}}$ with $Q^{\prime}$ as in Eq. (28). Gray contours in (a) and (b) are Montgomery potential $\left(\mathrm{ci}=0.5 \mathrm{~m}^{2} \mathrm{~s}^{-2}\right)$. 


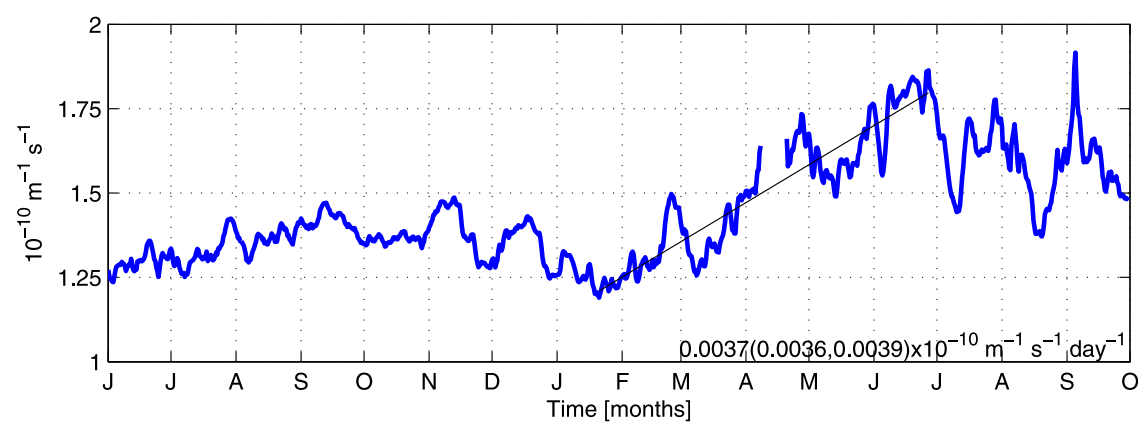

FIG. 7. Potential vorticity $f N^{2} / g$ on $25.375-\sigma_{\theta}$ surface averaged within the SRG from June 2004 to October 2005. The black line is a linear fit to the data between January and July 2005.

divergent EPVFs suggests that this may have been the cause of the increase in the SRG PV.

There were two events that led to enhanced crossfront divergent EPVFs along the mean path of the jet during the rapid increase of STMW PV. The first was the formation of a CCR from November 2004 to February 2005, which is the same CCR in Qiu et al. (2007) and will be referred to as CCR-A. The second was the interaction of the jet with a preexisting CCR, which formed downstream nearly a year before, and interacted with the KExt between March and July 2005 and will be referred to as CCR-B. The sequence of events can be seen in monthly-mean sea surface height (SSH) maps from satellite altimetry (Fig. 9). During CCR-A's formation and CCR-B's jet interaction there is enhanced cross-front divergent EPVFs beginning in October 2004 and seen in the time series of $v^{\prime} Q^{\prime}$ in Fig. 10 (top). The cumulative summation of the $v^{\prime} Q^{\prime}$ time series in Fig. 10 (bottom) clearly shows that these two events led to a net southward flux of eddy PV.
In an attempt to make a crude estimate of the contribution of STMW variability from cross-frontal exchange of PV, we make an estimate of the RHS of Eq. (26). Equation (26) can be approximated as

$$
\frac{\partial Q_{\mathrm{RG}}}{\partial t} \approx \frac{\kappa \Delta Q l}{4 A L}
$$

where the eddies are only acting over $\sim 1 / 4$ of the SRG circumference $l$, and the gradient of $\mathrm{PV}$ is approximated as $\nabla Q \cdot \mathbf{n} \approx \Delta Q / L$. From Fig. $8 \mathrm{c}$ the $\mathrm{PV}$ gradient can be approximated as $\Delta Q / L \approx 2 \times 10^{-10} \mathrm{~m}^{-1} \mathrm{~s}^{-1}$ per $50 \mathrm{~km}$. Additionally, if we approximate the SRG as a circle of radius $R=100 \mathrm{~km}$ with area $A=\pi R^{2}$ and circumference $l=2 \pi R$, an eddy diffusivity can be calculated for what is needed to balance Eq. (31):

$$
\kappa=\left(\frac{2 R L}{\Delta Q}\right) \frac{\partial Q_{\mathrm{RG}}}{\partial t}
$$
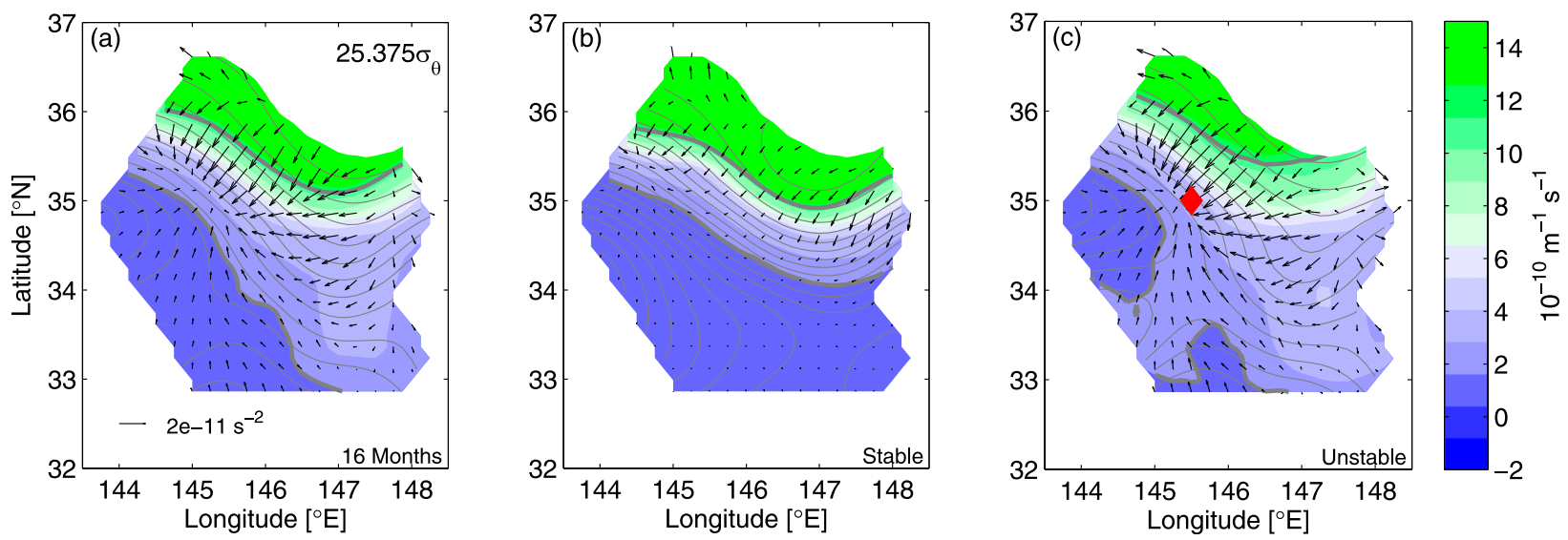

FIG. 8. Stable vs unstable eddy thickness flux. Divergent eddy thickness fluxes, $\alpha f \partial{\overline{\mathbf{u}^{\prime} T^{\prime}}}^{\text {div }} / \partial z$, along $25.375 \sigma_{\theta}$ for (a) 16 months, (b) stable, and (c) unstable regimes. Color contours are mean PV, $f N^{2} / g$, along $25.375 \sigma_{\theta}$ with ci $=1 \times 10^{-10} \mathrm{~m}^{-1} \mathrm{~s}^{-1}$. Gray contours are Montgomery potential $\left(\mathrm{ci}=1 \mathrm{~m}^{2} \mathrm{~s}^{-2}\right.$ ). The thick gray contours are the $2 \times 10^{-10}$ and $12 \times 10^{-10} \mathrm{~m}^{-1} \mathrm{~s}^{-1} \mathrm{PV}$ contours. The red diamond is the location of the time series in Fig. 10. 

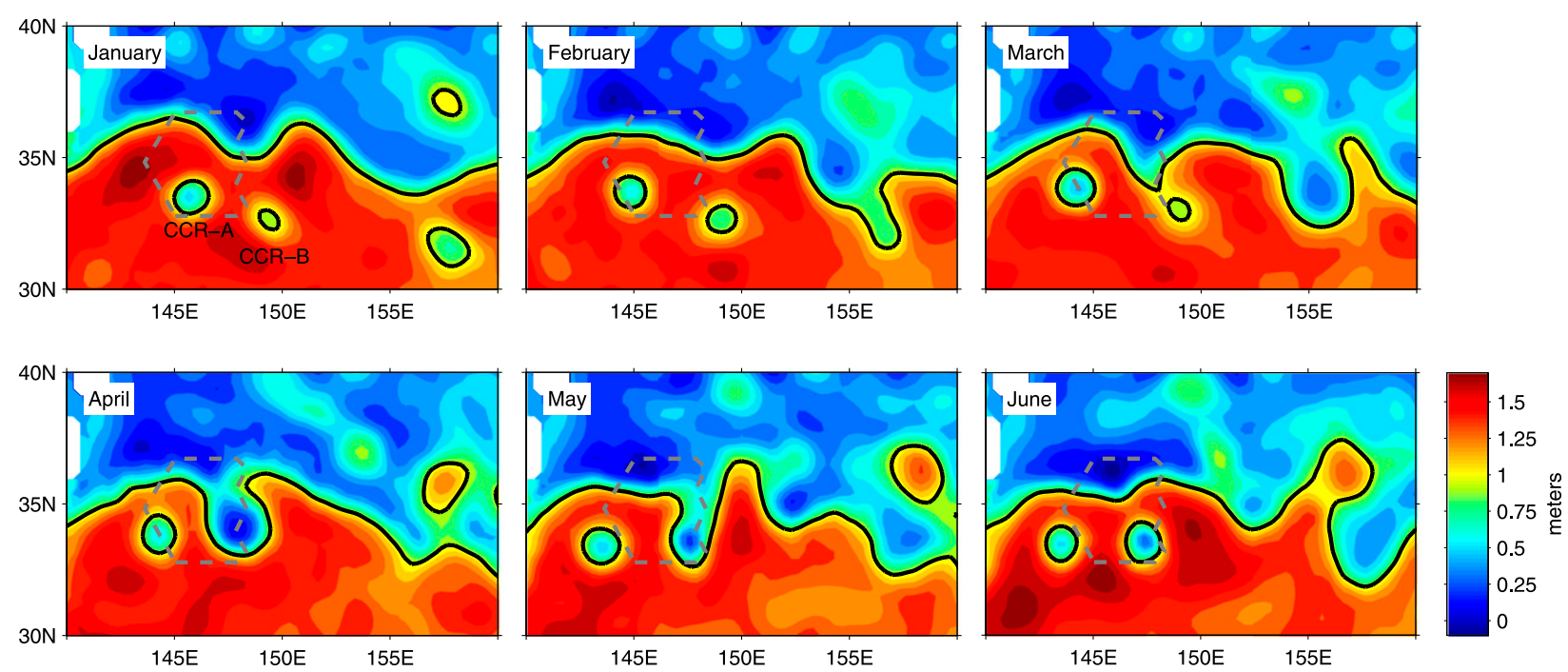

FIG. 9. Monthly-mean SSH from January to June 2005. Color contours are mean SSH from the AVISO-merged product with Centre National d'Études Spatiales (CNES)-CLS09 mean dynamic height ( $\mathrm{ci}=0.1 \mathrm{~m})$. The thick black contour is the $1-\mathrm{m}$ SSH contour marking the location of the jet axis. The thick gray dashed contour is the location of the KESS CPIES array used in this study.

Given the range of $\partial Q_{\mathrm{RG}} / \partial t$ from the $95 \%$ confidence intervals, eddy diffusivity would need to be $215(205,225)$ $\mathrm{m}^{2} \mathrm{~s}^{-1}$. These values are well within the range of eddy diffusivities in Fig. 5c. The area-averaged eddy diffusivity between $34.5^{\circ}-36^{\circ} \mathrm{N}$ and $144^{\circ}-145.5^{\circ} \mathrm{E}$ is $286 \mathrm{~m}^{2} \mathrm{~s}^{-1}$, which is close to $300 \mathrm{~m}^{2} \mathrm{~s}^{-1}$ found in Qiu et al. (2007). Cross-frontal eddy diffusion of PV due to mesoscale eddies more than compensates for the observed rapid change in STMW PV between January and June 2005.
In terms of additional sources or sinks of STMW PV, Qiu et al. (2007) show that the mixed layer depth within the SRG is much shallower during 2005 than in 2004 (320 vs $470 \mathrm{~m}$ at its maximum). They argue that the shallower wintertime mixed layer depth was unable to penetrate through the entire low PV STMW layer during the winter of 2005. Because of this, the source of new STMW PV water is arguably small from November 2004 to September 2005.
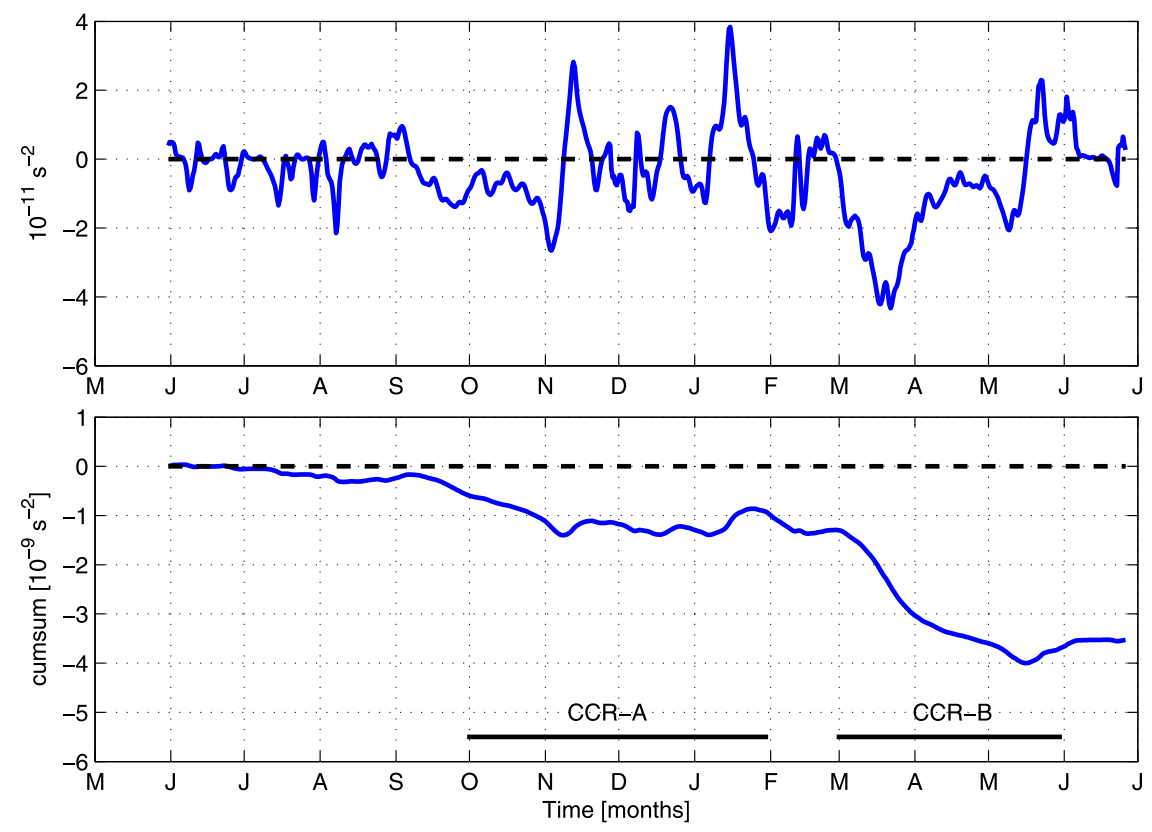

FIG. 10. Meridional eddy thickness flux $v^{\prime} Q^{\prime}$ time series at $145.5^{\circ} \mathrm{E}$ and $35^{\circ} \mathrm{N}$ (top) from June 2004 to July 2005. (bottom) Cumulative sum of the $v^{\prime} Q^{\prime}$ time series. 


\section{Conclusions}

In this study, we diagnose EPVFs within the STMW layer from CPIES observations made during KESS. It is shown that divergent eddy thickness fluxes are much larger than relative vorticity fluxes within the STMW layer in the KEx. The eddy thickness fluxes are mostly downgradient and are associated with strong convergence of PV adjacent to the SRG. The cross-front divergent EPVFs in the STMW layer provide a mechanism to modify STMW in the SRG. CCR formation and CCR-jet interaction were the mechanisms during KESS that drove large crossfrontal exchange of high PV waters from the north to the south side of the KEx. The large cross-front divergent EPVFs due to these processes coincided with the rapid increase of PV from January to July 2005 within the SRG. Eddy diffusivities diagnosed from the divergent EPVFs demonstrate that this cross-frontal exchange by eddies more than compensate for the increase in PV of the SRG. In addition to diffusion of PV as CCRs decay (Qiu et al. 2007), this study shows that the magnitude of the divergent EPVF is capable of being an additional mechanism that advects high PV into the low PV STMW waters. In Qiu et al. (2007), the increase in SRG PV from January to July 2005 was hypothesized to arise from eddy diffusion of high PV from the core of CCR-A with an eddy diffusivity of $300 \mathrm{~m}^{2} \mathrm{~s}^{-1}$. Our mapped observations of divergent EPVFs contradict this hypothesis because we did not find evidence of thickness flux convergence around CCR-A's path. We think that it was more likely the large cross-front EPVFs rather than the decay of CCR-A that led to the increase in the SRG PV. There must be some other mechanism driving the decay of the CCR-A than the eddy diffusion of thickness within the STMW layer. Unlike the ring, the north side of the KEx provides an infinite reservoir of high PV to be mixed with the low PV waters south of the front.

Acknowledgments. We thank Peter Gent and Frank Bryan for helpful comments that improved an early draft of this manuscript. The manuscript was also improved by the comments of Chief Editor Mike Spall and two anonymous reviewers. Karen Tracey, Kathy Donohue, and Andy Greene were instrumental in processing the CPIES data. This work was supported by the Advanced Study Program postdoctoral fellowship at the National Center for Atmospheric Research (NCAR) and under the National Science Foundation (NSF) Grants OCE0221008 and OCE08-51246 that funded KESS.

\section{REFERENCES}

Abernathey, R. P., and J. Marshall, 2013: Global surface eddy diffusivities derived from satellite altimetry. J. Geophys. Res., 118, 901-916, doi:10.1002/jgrc.20066.
Bishop, S. P., 2013: Divergent eddy heat fluxes in the Kuroshio Extension at $143^{\circ}-149^{\circ}$ E. Part II: Spatiotemporal variability. J. Phys. Oceanogr., 43, 2416-2431, doi:10.1175/JPO-D-13-061.1.

—, and D. R. Watts, 2013: Divergent eddy heat fluxes in the Kuroshio Extension at $143^{\circ}-149^{\circ}$ E. Part I: Mean structure. J. Phys. Oceanogr., 43, 1533-1550, doi:10.1175/JPO-D-12-0221.1.

Cronin, M. F., and D. R. Watts, 1996: Eddy-mean flow interaction in the Gulf Stream at $68^{\circ} \mathrm{W}$. Part I: Eddy energetics. J. Phys. Oceanogr., 26, 2107-2131, doi:10.1175/1520-0485(1996)026<2107: EFIITG $>2.0 . \mathrm{CO} ; 2$.

— , and Coauthors, 2013: Formation and erosion of the seasonal thermocline in the Kuroshio Extension recirculation gyre. Deep-Sea Res. II, 85, 62-74, doi:10.1016/j.dsr2.2012.07.018.

Cushman-Roisin, B., and J.-M. Beckers, 2011: Introduction to Geophysical Fluid Dynamics: Physical and Numerical Aspects. International Geophysics Series, Vol. 101, Academic Press, 828 pp.

Deremble, B., and W. Dewar, 2013: Volume and potential vorticity budgets of Eighteen Degree Water. J. Phys. Oceanogr., 43, 2309-2321, doi:10.1175/JPO-D-13-052.1.

Dewar, W., R. Samelson, and G. Vallis, 2005: The ventilated pool: A model of subtropical mode water. J. Phys. Oceanogr., 35, 137-150, doi:10.1175/JPO-2681.1.

Donohue, K. A., D. R. Watts, K. L. Tracey, M. Wimbush, and J.-H. Park, 2008: Program studies the Kuroshio Extension. Eos, Trans. Amer. Geophys. Union, 89, 161-162, doi:10.1029/ 2008EO170002.

,,,--- A. D. Greene, and M. Kennelly, 2010: Mapping circulation in the Kuroshio Extension with an array of current and pressure recording inverted echo sounders. J. Atmos. Oceanic Technol., 27, 507-527, doi:10.1175/ 2009JTECHO686.1.

Eden, C., R. J. Greatbatch, and J. Willebrand, 2007: A diagnosis of thickness fluxes in an eddy-resolving model. J. Phys. Oceanogr., 37, 727-742, doi:10.1175/JPO2987.1.

Flierl, G., and J. C. McWilliams, 1977: Sampling requirements for measuring moments of eddy variability. J. Mar. Res., 35, 797-820.

Fox-Kemper, B., R. Lumpkin, and F. O. Bryan, 2013: Lateral transport in the ocean interior. Ocean Circulation and Climate: A 21st Century Perspective, International Geophysics Series, Vol. 103, Elsevier, 185-210.

Gent, P. R., and J. C. McWilliams, 1990: Isopycnal mixing in ocean circulating models. J. Phys. Oceanogr., 20, 150-155, doi:10.1175/1520-0485(1990)020<0150:IMIOCM >2.0.CO;2.

Greene, A. D., D. R. Watts, G. G. Sutyrin, and H. Sasaki, 2012: Evidence of vertical coupling between the Kuroshio Extension and topographically controlled deep eddies. J. Mar. Res., 70, 719-747, doi:10.1357/002224012806290723.

Haynes, P., and M. E. McIntyre, 1987: On the evolution of vorticity and potential vorticity in the presence of diabatic heating and frictional or other forces. J. Atmos. Sci., 44, 828-841, doi:10.1175/1520-0469(1987)044<0828:OTEOVA > 2.0.CO;2.

— theorems for potential vorticity. J. Atmos. Sci., 47, 2021-2031, doi:10.1175/1520-0469(1990)047<2021:OTCAIT>2.0.CO;2.

Howe, P. J., K. A. Donohue, and D. R. Watts, 2009: Streamcoordinate structure and variability of the Kuroshio Extension. Deep-Sea Res., 56, 1093-1116, doi:10.1016/j.dsr.2009.03.007.

Iselin, C. O., 1939: The influence of vertical and lateral turbulence on the characteristics of the waters at mid-depths. Eos, Trans. Amer. Geophys. Union, 20, 414-417, doi:10.1029/ TR020i003p00414. 
Jayne, S. R., N. G. Hogg, and P. Malanotte-Rizzoli, 1996: Recirculation gyres forced by a beta-plane jet. J. Phys. Oceanogr., 26, 492-504, doi:10.1175/1520-0485(1996)026<0492: RGFBAB $>2.0 . C O ; 2$.

Marshall, J., and G. Shutts, 1981: A note on rotational and divergent eddy fluxes. J. Phys. Oceanogr., 11, 1677-1679, doi:10.1175/ 1520-0485(1981)011<1677:ANORAD>2.0.CO;2.

— serving the cycle of convection and restratification over the Gulf Stream. Bull. Amer. Meteor. Soc., 90, 1337-1350, doi:10.1175/2009BAMS2706.1.

Mizuno, K., and W. B. White, 1983: Annual and interannual variability in the Kuroshio Current System. J. Phys. Oceanogr., 13, 1847-1867, doi:10.1175/1520-0485(1983)013<1847: AAIVIT $>2.0 . \mathrm{CO} ; 2$.

Montgomery, R. B., 1940: The present evidence on the importance of lateral mixing processes in the ocean. Bull. Amer. Meteor. Soc., 21, 87-94.

Oka, E., and B. Qiu, 2012: Progress of North Pacific mode water research in the past decade. J. Oceanogr., 68, 5-20, doi:10.1007/s10872-011-0032-5.

Qiu, B., and S. Chen, 2005: Variability of the Kuroshio Extension jet, recirculation gyre, and mesoscale eddies on decadal time scales. J. Phys. Oceanogr., 35, 2090-2103, doi:10.1175/JPO2807.1.

— North Pacific Subtropical Mode Water: Oceanic versus atmospheric control. J. Phys. Oceanogr., 36, 1365-1380, doi:10.1175/JPO2918.1.

, P. Hacker, S. Chen, K. A. Donohue, D. R. Watts, H. Mitsudera, N. G. Hogg, and S. R. Jayne, 2006: Observations of the subtropical mode water evolution from the Kuroshio Extension System Study. J. Phys. Oceanogr., 36, 457-473, doi:10.1175/JPO2849.1.
_ S. Chen, and P. Hacker, 2007: Effect of mesoscale eddies on subtropical mode water variability from the Kuroshio Extension System Study (KESS). J. Phys. Oceanogr., 37, 982-1000, doi:10.1175/JPO3097.1.

Rainville, L., S. R. Jayne, J. L. McClean, and M. E. Maltrud, 2007: Formation of subtropical mode water in a high-resolution ocean simulation of the Kuroshio Extension region. Ocean Modell., 17, 338-356, doi:10.1016/j.ocemod.2007.03.002.

Ringler, T., and P. Gent, 2011: An eddy closure for potential vorticity. Ocean Modell., 39, 125-134, doi:10.1016/ j.ocemod.2011.02.003.

Smith, W. H. F., and D. T. Sandwell, 1997: Global seafloor topography from satellite altimetry and ship depth soundings. Science, 277, 1957-1962, doi:10.1126/science.277.5334.1956.

Talley, L. D., 1988: Potential vorticity distribution in the North Pacific. J. Phys. Oceanogr., 18, 89-106, doi:10.1175/ 1520-0485(1988)018<0089:PVDITN>2.0.CO;2.

Tracey, K. L., D. R. Watts, K. A. Donohue, and H. Ichikawa, 2012: Propagation of Kuroshio Extension meanders between $143^{\circ} \mathrm{E}$ and $149^{\circ}$ E. J. Phys. Oceanogr., 42, 581-601, doi:10.1175/ JPO-D-11-0138.1.

Treguier, A. M., I. M. Held, and V. D. Larichev, 1997: Parameterization of quasigeostrophic eddies in primitive equation ocean models. J. Phys. Oceanogr., 27, 567-580, doi:10.1175/ 1520-0485(1997)027<0567:POQEIP > 2.0.CO;2.

Waterman, S. N., and S. R. Jayne, 2011: Eddy-mean flow interactions in the along-stream development of a western boundary current jet: An idealized model study. J. Phys. Oceanogr., 41, 682-707, doi:10.1175/2010JPO4477.1.

Wilson, C., and R. G. Williams, 2004: Why are eddy fluxes of potential vorticity difficult to parameterize? J. Phys. Oceanogr., 34, 142-155, doi:10.1175/1520-0485(2004)034<0142: WAEFOP $>2.0 . \mathrm{CO} ; 2$. 